\title{
Introdução: Leituras do país dos "descobrimentos" no final do século XX
}

\section{Pedro Cerdeira}

Université de Genève

Instituto de História Contemporânea

Universidade Nova de Lisboa

-pedro.cerdeira@unige.ch

Dol https://doi.org/10.34913/

journals/lingua-lugar.2020.e204 
A Expo'98, a Exposição Internacional de Lisboa, esteve aberta ao público na capital portuguesa entre 22 de maio e 30 de setembro de 1998. A exposição contou com 160 participantes (146 países e 14 organizações internacionais) distribuídos por 126 pavilhões. A Expo'98 constituiu uma oportunidade de redefinição interna e sobretudo externa da imagem de Portugal, então apresentado como um país moderno, integrado na Comunidade Europeia, voltado para o futuro (Relatório, 1999; Ferreira, 2006).

O mote escolhido foi "Os Oceanos, um Património para o Futuro", integrando preocupações ambientais e de sustentabilidade, articuladas com as possibilidades de exploração dos recursos marítimos. Mas os oceanos foram também associados à história do país anfitrião e ao seu papel na expansão marítima dos séculos XV e XVI. O elemento histórico foi assumido de forma oficial, como indicado pelo próprio governo português no momento da criação do Comissariado da Expo'98, em 1993 (Relatório, 1999).

O relatório final da exposição apresentado ao Bureau International des Expositions - entidade que tutela as exposições internacionais e universais - insiste em questões como a exploração sustentável dos recursos dos oceanos, as preocupações ambientais, a grande escala da própria operação urbanística do recinto. ${ }^{1}$ Não deixa, no entanto, de chamar a atenção para a efeméride e o passado de Portugal enquanto país pioneiro da expansão marítima.

\footnotetext{
1 Neste âmbito, Claudino Ferreira constata a periferização das exposições internacionais a partir da Segunda Guerra Mundial: "são cada vez mais cidades centrais de países semiperiféricos ou cidades periféricas de países centrais que se entregam a estes projetos", sendo aí que se revelam instrumentos úteis de projeção (Ferreira, 1998, p. 47).
} 
Na verdade, a Expo'98 partiu de uma proposta da Comissão Nacional para as Comemorações dos Descobrimentos Portugueses (CNCDP), "a qual [teve] por objetivo um conjunto variado de ações tendentes a assinalar a relevância histórica dos descobrimentos portugueses das últimas décadas do século XV" (Relatório, 1999, p. 18). O ano de 1998 marcava o quinto centenário da chegada de Vasco de Gama à Índia. De acordo com Abílio Morgado, diretor de Relações Externas da Expo'98 e autor do relatório final da exposição, esse acontecimento teria permitido "aquele que foi um intercâmbio cultural de consequências riquíssimas para a Humanidade" (Relatório, 1999, p. 18).

A CNCDP esteve ativa entre 1986 e 2002, constituindo a sua criação e o seu programa uma mobilização da história por parte do estado português (Cardão, 2019), ainda que não de forma totalmente consensual, mesmo dentro da própria comissão, ${ }^{2}$ pelo que a exposição caiu no mesmo "espaço de disputa simbólica e ideológica" das comemorações (Ferreira, 2006, p. 222).
2 Dado que a CNCDP atravessa diferentes governos, tendo vários comissários- gerais, apenas se demarca de leituras mais nacionalistas a partir da nomeação de António Manuel Hespanha como comissário-geral no final de 1995 (Ferreira, 2006, pp. 234 e seguintes).

\section{Exposições internacionais, história e identidade nacionais}

Por um lado, a Expo'98 inscreve-se na tradição das exposições universais e internacionais iniciada em meados do século XIX. Tais exposições, cujas origens se convencionou estabelecer na Grande Exposição de Londres de 1851, foram desde o início fóruns internacionais de progresso e modernidade, onde se confrontavam os feitos industriais (e depois também artísticos) dos países do mundo ocidental (Vicente, 2003).

Por outro lado, verifica-se igualmente uma continuidade entre as comemorações do final do século XX e as do século XIX. A chegada de Vasco da Gama à Índia tinha já sido objeto de celebração em Portugal, em 1898, ano em que foram organizadas as Comemorações do IV Centenário da Índia (Ferreira, 2006).

Ou seja, não só a ideia do certame como montra da nação é antiga, como uma das declinações do tema proposto - a do passado histórico inscreve-se também numa lógica de continuidade.

Com efeito, leituras do contacto português com os oceanos tinham sido propostas em certames anteriores. Por um lado, na representação portuguesa em exposições no estrangeiro, como são as participações nas exposições de Paris (1937) e Nova lorque (1939) (Acciaiuoli, 1998); 
por outro lado, enquanto tema e ambiente de certames nacionais, como aconteceu com as já referidas comemorações de 1898, a Exposição Colonial de 1934 e a Exposição do Mundo Português de 1940. Nesse sentido, a Expo'98 foi uma exposição que visava alavancar o futuro a partir deste passado. Não só pela efeméride em si, mas por revisitar um tema que outros regimes políticos em Portugal já tinham utilizado, em particular o Estado Novo.

No entanto, a presença do colonialismo em exposições não é uma especificidade portuguesa. Se desde o seu início as exposições universais e internacionais mantiveram a sua ambição de serem montras do progresso, foram também utilizadas enquanto produtoras de identidade, algo patente por exemplo no facto de França ter acrescentado a secção de Belas-Artes enquanto traço distintivo das suas exposições (Vicente, 2003). Se o elemento definidor da identidade das nações em exposição era o progresso (tecnológico, associado ao crescimento económico), as representações nacionais acabariam por incorporar outros elementos.

Foi o que aconteceu com a colonização de territórios africanos e asiáticos no final do século XIX, um novo espaço de competição entre as potências europeias que cedo se refletiu nas representações presentes nas exposições. Assim, a dominação colonial entrou nas exposições e a "capacidade" colonizadora europeia participou na construção das identidades nacionais. A partir da década de 1860, "exemplares" das populações colonizadas foram expostos nas exposições, que passaram a incluir secções coloniais, para além de serem organizadas exposições coloniais propriamente ditas (Galopin, 1997; Vicente, 2003; Ferreira, 2006). Também em Portugal, em particular sob o Estado Novo, tal se passou, sendo as Exposições Colonial de 1934 e do Mundo Português de 1940 disso exemplo. Como pelo resto da Europa, secções e exposições coloniais tentavam demonstrar os sucessos e os benefícios da presença colonial.

Como sintetiza Claudino Ferreira, "[a] participação portuguesa nas Expos deste período [até 1939], (...), inscreveu-se claramente nesta tendência. Ao lado dos objetos ilustrativos das tradições artesanais e artísticas do país e dos produtos agrícolas e industriais, comparativamente insignificantes face às grandes potências económicas, o elemento central das representações portuguesas eram as mostras coloniais" (Ferreira, 2006, p. 156).

O Estado Novo, na continuidade de um esforço já demonstrado pela Monarquia Constitucional e pela Primeira República, estabeleceu a manutenção do império como elemento definidor da nação, e as 
exposições foram instrumentos de prossecução desse objetivo, dedicando salas e pavilhões à demonstração do papel de Portugal na expansão marítima e dos sucessos da sua presença colonial.

\section{O país dos "descobrimentos" no final do século XX: que história para Portugal?}

As exposições internacionais podem ser vistas como espaços de "propaganda ideológica" e de inculcação de programas, algo já verificado nas exposições e representações do Estado Novo (Ferreira, 2006; Acciaiouli, 1998). São também óbvios espaços e ocasiões de valorizar internacionalmente os países e as cidades de acolhimento (Ferreira, 1998).

Com o desmantelamento dos impérios coloniais europeus e a introdução de novos paradigmas epistemológicos (dos quais emergirão os estudos pós-coloniais), as exposições passaram por uma "reformulação doutrinária" na segunda metade do século XX, tentando substituir um discurso colonialista e eurocêntrico por "novos desígnios de alcance global e humanista" (Ferreira, 2006, pp. 181-182).

Alinhando com esta leitura e apresentando a Expo'98 traços de continuidade em relação ao momento da história nacional que utiliza (tal como foi assumido pelo governo e pela CNCDP), é pertinente escrutinar como foi essa história apropriada e apresentada nesse novo contexto, já que, como indica Marcos Cardão, no que diz respeito à CNCDP, "a revisão historiográfica não terá impedido a proliferação de releituras nacionalistas, nem a reconfiguração de significados das iniciativas da Comissão" (Cardão, 2019, p. 29).

O facto de a Expo'98 ter lugar num Portugal democrático, "europeu" e pós-imperial, leva-nos a questionar a leitura que propôs da história nacional: o que valorizou, o que silenciou, o que escamoteou.

A ditadura do Estado Novo, na sua fase final, enveredou por um discurso luso-tropicalista: apropriando-se das teorias do sociólogo brasileiro Gilberto Freyre, o estado português defendia o colonialismo português como imbuído de um elemento diferenciador e favorável quando em comparação com os restantes colonialismos. Partia do pressuposto segundo o qual os portugueses teriam uma tendência e uma capacidade inatas para se relacionar com os outros povos de forma pacífica e tolerante, tendo dessa forma dado alegadamente origem a sociedades miscigenadas desprovidas de preconceito (Castelo, 1998). Essa ideia de excecionalidade parece ter perdurado nas 
representações do país, mesmo depois do fim do império (Cardão, 2018). Interessa por isso perceber como se situou a Expo'98 nesse mapa de ideias, pretendendo conciliar uma história "heroica" com os desafios de narrativas universalistas.

$\mathrm{Na}$ verdade, vestígios da continuidade de uma leitura luso-tropicalista da história aparecem dispersos pela exposição, até em termos espaciais: os Jardins Garcia de Orta propunham ao visitante um percurso botânico organizado de acordo com as zonas geográficas do antigo império colonial.

A Expo'98 não foi ainda alvo de um significativo investimento analítico. A tese de doutoramento de Claudino Ferreira, que examina do ponto de vista sociológico a preparação da exposição, continua a ser o trabalho mais abrangente sobre o tema (Ferreira, 1998, 2006).

A Expo'98 suscitou maior interesse no âmbito do urbanismo e da antropologia do espaço, com alguns trabalhos feitos imediatamente a seguir à realização da exposição. ${ }^{3}$

3 Por exemplo, Ferreira, V. M e Indovina, F. (1999). A cidade da Expo'98: uma reconversão na frente ribeirinha de Lisboa?. Lisboa: Bizâncio.

No entanto, o discurso associado à Expo'98 apenas recentemente começou a ser objeto de uma análise sistemática e sustentada no universo da historiografia. O número 8 da revista Práticas da História, publicado em 2019, em torno das formas de comemoração dos descobrimentos portugueses, constituiu um contributo decisivo.

Neste contexto, o presente dossiê pretende ser um contributo para o entendimento do impacto de iniciativas comemorativas e da construção da identidade nacional no Portugal contemporâneo a partir do estudo de caso da Expo'98 e de produtos culturais a ela associados. Fá-lo de uma forma multidisciplinar, reunindo intervenções vindas não apenas da área da história, mas também das ciências da comunicação, das ciências da educação e dos estudos literários. O dossiê convida assim o leitor a olhar um mesmo objeto a partir de diferentes perspetivas.

Em particular, interessa-nos questionar a forma como uma das vertentes do tema "oceanos" se declinou na exposição, designadamente a história de Portugal, com particular enfoque no denominado período dos descobrimentos e respetiva apropriação e (re)significação no processo de construção de narrativas identitárias. As contribuições deste dossiê têm origem num ateliê organizado pelo Centre d'Études Lusophones da Université de Genève em novembro de 2018, que reuniu investigadores das diferentes disciplinas aqui representadas para discutir o tema. 
Este dossiê não esgota, contudo, as possibilidades de análise destas questões. A título de exemplo, a comparação de exposições e momentos comemorativos na época contemporânea em regimes de orientação política diversa constituiria uma via de pesquisa e análise frutífera, tal como a do exame sustentado do impacto e longevidade das narrativas identitárias propostas por acontecimentos desta natureza junto do público visitante e da população em geral.

\section{Percurso de uma exposição}

Este dossiê parte da exposição mas não se limita a ela, integrando a análise de produtos culturais que Ihe foram associados. Estão nesta categoria a telenovela Terra Mãe, na qual a própria exposição surge encenada e integrada no enredo, e a ópera Corvo Branco. Esta última foi originalmente pensada para a programação de Lisboa, Capital Europeia da Cultura (1994), mas apenas estreou no recinto da Expo'98 e já perto do final da exposição, como parte do ciclo dos eventos complementares. Interessa-nos interrogar de que forma estas produções contribuíram para a leitura do papel do país no processo da expansão marítima e perceber que narrativa sobre identidade nacional propõem e como foram as ideias de expansão, colonialismo e "intercâmbio cultural" utilizadas pela organização da exposição e pela classe política portuguesa.

Podemos considerar que este dossiê contém em si um percurso. Abre com um exercício de comparação entre a Expo'98 e a anterior exposição de grande envergadura que a cidade de Lisboa acolheu, a Exposição do Mundo Português, em 1940.

No seu artigo, Pedro Martins assinala o espaço que uma e outra dão à história nacional, particularmente ao período da expansão marítima, e analisa a forma como este período foi utilizado por ambas as exposições, ao nível dos discursos e das manifestações arquitetónicas e performativas das exposições. Aponta as diferenças entre os dois eventos, enquadrando-os nos respetivos contextos.

Através de uma argumentação abundantemente documentada, o autor demonstra como as duas exposições assumiram o período da expansão como o elemento fundamental da identidade portuguesa, sendo reiterado o papel de Portugal no encontro de culturas. Tal foi conseguido através de uma opção clara de apresentar uma determinada leitura da expansão que negligenciou as dimensões económica e política, em favor de aspetos religiosos e culturais, e cujos processos e resultados foram branqueados. 
Pedro Martins salienta que "[tendo] em conta as circunstâncias que rodearam a desagregação do império português, os sucessivos governos têm optado por comemorar os aspetos alegadamente positivos da chamada 'expansão portuguesa', lançando um olhar de silêncio sobre o lado negativo ou violento do colonialismo português e dos seus legados".

A propósito das significações atribuídas ao momento comemorativo da Expo'98, o artigo convoca diferentes atores e intervenientes (políticos, intelectuais, associações), demonstrando o modo como o passado, longe de estanque, é um território de disputa e negociação.

Seguem-se dois estudos de caso relacionados com conteúdos e eventos associados à exposição.

Marta Araújo concentra-se no estudo do conteúdo expositivo do pavilhão do país anfitrião da Expo'98 - o Pavilhão de Portugal - e a forma como nele se reconstruiu a história da expansão. Em causa está um filme, exibido numa das salas do pavilhão, sobre a chegada dos portugueses ao Japão inspirado na iconografia dos biombos Nambam, que a autora defende servir uma estratégia de naturalização da despolitização da história da expansão portuguesa através da multiperspetividade. De acordo com esta proposta teórica, o preconceito é algo comum a todas as culturas (as populações brancas não serão as únicas produtoras de preconceito), um pressuposto que a autora identifica noutras formas de divulgação da história de então. Efetivamente, a multiperspetividade encontra na época um contexto propício: organismos como o Conselho da Europa e a UNESCO promoviam-no nessa década de 1990 como princípio da didática da história, segundo o qual se deveriam privilegiar diferentes perspetivas sobre um mesmo assunto.

Assim, para além dessa concretização no filme exibido no Pavilhão de Portugal, a multiperspetividade encontra-se também plasmada no discurso dos manuais escolares de história em Portugal, no que diz nomeadamente respeito à expansão e aos fenómenos da colonização e da escravatura.

A autora considera, no entanto, que "os debates sobre multiperspetividade são frequentemente reduzidos ao mero contrastar de diferentes pontos de vista, sem qualquer consideração sobre poder e produção de conhecimento, designadamente a relação entre projetos políticos e epistemológicos". Daqui resulta a naturalização de uma Europa como espaço natural dos europeus e a historiografia europeia como paradigma 
científico de referência. Deste modo, Marta Araújo sublinha os limites da multiperspetividade, que no fundo contribui para uma leitura "descontextualizada e despolitizada da história colonial", pois não questiona as relações de poder da produção de conhecimento, reforçando, pelo contrário, uma perspetiva eurocêntrica e, no que diz respeito à expansão, uma narrativa "vitoriosa" para Portugal. O filme em questão não só reutiliza dispositivos antigos de hierarquização racial (traços físicos), como se foca no encontro em Portugal e Japão, "o país asiático mais embranquecido na história".

Já o texto de Nazaré Torrão e Octavio Páez Granados constitui uma análise inédita da ópera Corvo Branco, com música de Philip Glass e libreto de Luísa Costa Gomes, encomendada pela CNCDP e estreada em Lisboa por ocasião da Expo'98.

Os autores dissecam um texto carregado de símbolos, demonstrando como a obra recorre a "universos simbólicos" e "mitos" vulgarizados e, portanto, facilmente reconhecidos e consumidos pelo público (português).

Corvo Branco destaca-se por configurar um exemplo mais conseguido de desconstrução do imaginário de heróis associado aos descobrimentos, ao propor uma leitura mais diversificada da noção de descoberta (por imposição do compositor). Tenta também dar um lugar na história a todos os que permitiram a expansão, incluindo os trabalhadores da construção naval, e consequentemente alargando a categoria de herói. Da mesma forma, o libreto não esconde a relação de poder desigual estabelecida entre portugueses e as populações dos locais a que chegaram e alude mesmo à situação neocolonial.

Os autores consideram Corvo Branco como uma obra com algumas ambiguidades, em que as estratégias de pulverização da narrativa (espacial e temporalmente) e de colagem de textos, se por um lado configuram de forma crítica a superabundância de tempo, acontecimentos e lugares (a partir de Marc Augé), podem levar à dispersão e à imprecisão do que é relatado, abrindo espaço a essas ambiguidades ou a leituras truncadas. $\dot{E}$ interessante ver, por exemplo, como os excertos escolhidos na colagem de textos são na sua maioria aqueles que "esvaziam os espaços das populações autóctones" e que o libreto não se demite de uma "heroicização" dos navegadores. 
Por outro lado, é a pluralidade dos discursos e a utilização da ironia que permitem aos autores encontrar na obra uma forma de comentário crítico, dando Corvo Branco conta de que "a sociedade não verbaliza deliberadamente as passagens menos gloriosas da história". A obra consegue por isso abrir um espaço de crítica, ironizando, por exemplo, a propósito do cinismo neocolonial.

O último artigo deste dossiê conduz-nos para fora da exposição, designadamente até à forma como a televisão tentou levar a exposição para fora dela e para o público telespetador, dispensando a aquisição de bilhete para uma exposição que aconteceu apenas em Lisboa. A partir de um produto popular e de ampla difusão, Catarina Duff Burnay propõe uma leitura igualmente inédita da telenovela Terra Mãe, produzida e transmitida pela Rádio Televisão Portuguesa (canal público em sinal aberto) em 1998.

Este estudo de caso reveste-se de particular interesse pois, como afirma Marcos Cardão, a televisão é o meio de comunicação "mais eficaz a permitir a construção de uma memória coletiva comum, a fomentar a consciência nacional e a reforçar a imaginação nacional" (Cardão, 2019, p. 19). Um confronto com o caso de Corvo Branco e o seu espaço de crítica a um determinado discurso poderia levar-nos a questionar o real impacto das duas obras, já que essa obra de Philip Glass tem sido muito pouco levada à cena e o género operático é ainda pensado de forma bastante elitista.

Catarina Duff Burnay demonstra como, enquanto potencial promotora de agendas e de construção de coesão, Terra Mãe fez largo uso de uma ideia de Portugal como o país que tornou possível o "encontro de culturas", ideia plasmada em determinados personagens e aspetos do enredo. A autora constata que o conteúdo da telenovela "parece favorecer a construção de uma narrativa branda, ignorando, por exemplo, o passado histórico de relações, como o período dos descobrimentos e as suas consequências para os povos das ex-colónias", sendo que a "representação pacificada da relação entre povos diferentes é pontuada pelo recurso ao reforço de estereótipos". Portanto, uma leitura branqueada e despolitizada do passado.

Em particular, a autora consegue mapear um imaginário ligado à expansão marítima e uma imagem de cariz luso-tropical da presença colonial portuguesa. Esse imaginário está presente desde logo no próprio título e no genérico da telenovela, sendo depois elaborado nas três perso- 
nagens originárias de territórios que foram colónias portuguesas (Brasil, Moçambique) ou que então à época ainda administrados por Portugal (Macau), que se reúnem em Lisboa, em casa de uma portuguesa, todos em busca de melhores oportunidades. A relação amorosa principal da trama é mesmo entre um brasileiro e uma portuguesa.

Da mesma forma, a telenovela em questão promoveu também uma imagem de modernização do país e da cidade de Lisboa, através da arquitetura e do urbanismo e das tecnologias de comunicação e informação, pelo que Terra Mãe se coadunou deste modo também com a proposta dos próprios organizadores da exposição quanto ao assumido desejo de modernização fomentado pela Expo'98.

As exposições internacionais são um fenómeno marcante da época contemporânea, tendo persistido até ao presente como campo de exibição e competição dos países. Esta longevidade explica-se, também, pela demonstrada capacidade de se reinventarem como dispositivos e de se adaptarem a contextos diferenciados. As continuidades e diferenças no manuseamento de um legado colonial configura um exemplo elucidativo do que se acaba de afirmar. País pioneiro no processo da expansão marítima, Portugal (através das suas classes políticas e intelectuais) tem usado, de forma consistente, esse momento da história nacional como o mais importante na definição de uma identidade nacional. Trata-se de um processo longe de linear e unívoco, ainda que frequentemente percorrido pela tentativa de consensualizar uma interpretação do passado, vital na configuração identitária de cada presente. Metrópole de um império colonial desmantelado entre 1974 e 1975, a imagem escolhida para apresentar o país ao mundo em 1998 resgatou novamente o período da expansão marítima, ainda como o seu momento áureo e de maior contributo para a história mundial, omitindo grandemente a violência e a disrupção que esse processo representou para diferentes sociedades. Os diversos elementos e dispositivos analisados neste dossiê parecem de facto corroborar a existência de uma leitura parcial, seletiva e positivamente valorada do papel de Portugal na expansão. O grau de continuidade temática (e respetivas replicações expositivas) entre a Exposição do Mundo Português e a Expo'98, bem como o filme exibido no Pavilhão de Portugal sobre a chegada dos portugueses ao Japão e as escolhas temáticas e narrativas da telenovela Terra Mãe tomam de empréstimo e reciclam noções de luso-tropicalismo e de um encontro pacífico com o outro, mais conforme a um gosto cosmopolita e uma retórica de globalização. A ópera Corvo Branco, por outro lado, constitui um espaço de alguma crítica, confirmando como estes processos de construção 
e afirmação das identidades não são unívocos, mas sim complexos e disputados. Não se afastando demasiado do imaginário dos descobrimentos, Corvo Branco consegue de alguma forma desconstruí-lo e criticar visões romantizadas sobre esse período e a situação neocolonial.

\title{
Bibliografia
}

Acciaiuoli, M. (1998). Exposições do Estado Novo. 1934-1940. Livros Horizonte.

Cardão, M. (2018). "Foram oceanos de amor: Os descobrimentos portugueses na cultura pop dos anos $80^{\prime \prime}$. Portuguese Studies Review, 26 (1), 99-148.

- (2019). “A grande aventura. Televisão, nacionalismo e as comemorações dos Descobrimentos portugueses". Práticas da História, Journal on Theory, Historiography and Uses of the Past, 8, 11-47.

Castelo, C. (1998). O Modo Português de Estar no Mundo. O Luso-Tropicalismo e a Ideologia Colonial Portuguesa (1933-1961). Porto: Edições Afrontamento.

Ferreira, C. (1998). “A Exposição Mundial de Lisboa de 1998: contextos de produção de um mega-evento cultural". Revista Crítica de Ciências Sociais, 51, 43-67.
- (2006). A Expo'98 e os Imaginários do Portugal Contemporânea. Cultura, celebração e políticas de representação. Tese de Doutoramento em Sociologia. Faculdade de Economia da Universidade de Coimbra.

Galopin, M. (1997). As exposições internacionais do século XX e o BIE. Lisboa: Expo'98.

Relatório. Exposição Mundial de Lisboa de 1998. (1999). Lisboa: Parque Expo'98, S.A.

Vicente, F. L. (2003). Viagens e Exposições: D. Pedro V na Europa do Século XIX. Lisboa: Gótica.

\author{
(a)
}

